\title{
O ENSINO DE MATEMÁTICA NA EDUCAÇÃO PROFISSIONAL TÉCNICA: UMA ANÁLISE CURRICULAR
}

\author{
Harryson Júnio Lessa Gonçalves (UNESP)* \\ Ana Lúcia Braz Dias (CMU/EUA)** \\ Deise Aparecida Peralta (UNESP)***
}

\section{RESUMO}

O artigo visa, a partir da caracterização da Educação Profissional e Tecnológica no sistema educacional brasileiro, discutir necessidades, dificuldades e estratégias didáticas apresentadas por professores brasileiros sobre a Matemática em cursos técnicos da área de indústria de uma escola pública do Brasil. Para tanto, conduziu-se uma pesquisa qualitativa, construída a partir dos seguintes procedimentos metodológicos: visitas técnicas à escola investigada, análise de currículos e entrevistas com professores. 0 estudo revela que a matemática na educação profissional técnica (concomitante/subsequente) apresenta-se como base tecnológica, devendo então estar atrelada à formação matemática dos alunos, superando perspectivas meramente instrumentais de ensino.

Palavras chave: Ensino de matemática. Currículo de matemática. Educação profissional. Ensino técnico.

\section{ABSTRACT}

\section{THE TEACHING OF MATHEMATICS IN TECHNICAL PROFESSIONAL EDUCATION: A CURRICULAR ANALYSIS}

The article delineates the Brazilian system of Professional and Technological Education and discusses the necessities, difficulties and didactical strategies of Brazilian teachers relating to mathematical content in technical courses of the area of Industry in a public school in Brazil. For this we conducted a qualitative

Doutor em Educação Matemática pela Pontifícia Universidade Católica de São Paulo (PUC/SP). Professor na Faculdade de Engenharia de Ilha Solteira (FEIS) da Universidade Estadual Paulista "Júlio de Mesquita Filho" (UNESP). Membro do Grupo de Pesquisa em Currículo: Estudos, Práticas e Avaliação (GEPAC/UNESP). Docente credenciado no Programa de Pós-Graduação em Ensino e Processos Formativos (UNESP) e no Programa de Pós-Graduação em Educação para a Ciência (UNESP). E-mail: harryson.lessa@unesp.br

** Doutora em Educação Matemática pela Indiana University (IU/EUA). Professora da Central Michigan University (CMU/EUA). Membro do Grupo de Pesquisa em Currículo: Estudos, Práticas e Avaliação (GEPAC/UNESP). Pesquisadora visitante no Programa de Pós-Graduação em Ensino e Processos Formativos (UNESP). E-mail: dias1al@cmich.edu

*** Doutora em Educação para a Ciência pela Universidade Estadual Paulista "Júlio de Mesquita Filho" (UNESP). Professora na Faculdade de Engenharia de Ilha Solteira (FEIS) da Universidade Estadual Paulista "Júlio de Mesquita Filho" (UNESP). Membro do Grupo de Pesquisa em Currículo: Estudos, Práticas e Avaliação (GEPAC/UNESP). Docente credenciada no Programa de Pós-Graduação em Ensino e Processos Formativos (UNESP). E-mail: deise.peralta@unesp.br 
study based on technical visits to the school investigated, analysis of curricula and teacher interviews. The study reveals that, in the different modalities of professional and technical education (concomitant/subsequent), mathematics is presented in the curriculum as what is called "technological base", and that it must, therefore, be part of the students' education, going beyond merely instrumental perspectives of teaching.

Keywords: Teaching math. Mathematics curriculum. Vocational education. Technical education.

\section{RESUMEN}

\section{LA ENSEÑANZA DE MATEMÁTICA EN LA EDUCACIÓN PROFESIONAL TÉCNICA: UN ANÁLISIS CURRICULAR}

El artículo busca, desde la caracterización de la Educación Profesional y Tecnológica en el sistema educativo brasileño, discutir necesidades, dificultades y estrategias didácticas presentadas por los profesores brasileños acerca de la matemática en cursos técnicos del área industrial en una escuela publica de Brasil. Con este propósito, una investigación cualitativa se llevó a cabo, construida a partir de los siguientes procedimientos metodológicos: visitas técnicas a la escuela investigada, análisis de los planes de estudio y entrevistas con los profesores. El estudio revela que la matemática en la educación profesional técnica (concurrente/posterior) se presenta como una base tecnológica y luego deben estar vinculados a la formación matemática de los estudiantes, superando las perspectivas de enseñanza meramente instrumentales.

Palabras clave: Enseñanza de las matemáticas. Currículo de matemáticas. Educación professional. Educación técnica.

\section{Introdução}

A educação profissional tem sido definida de forma variada em diferentes países. As legislações que regem esse segmento da educação são diversas, assim como os fatores sociais, econômicos e culturais que os afetam. No entanto, em um mundo dito de cultura globalizada, os sistemas de educação profissional enfrentam desafios semelhantes em diferentes países e têm a missão geral de preparar os alunos para carreiras e empregos, concentrando-se no desenvolvimento de conhecimentos e habilidades específicas da profissão.

No contexto da Educação Matemática, a contextualização da matemática em situações realistas (Educação Matemática Realista de Freudenthal), o uso da modelagem matemática como estratégia de ensino e uma abordagem interdisciplinar para a educação matemática têm sido um foco de pesquisas e recomendações há muitas décadas (BARBOSA, 2001; LOZADA, 2007).

As conexões entre educação profissional e ensino de Matemática tomam então uma dimensão óbvia, pois somos levados a perguntar se a educação profissional e técnica, cujo objetivo é preparar alunos para a atuação no mundo do trabalho, não seria um contexto em que a Matemática aparecesse por excelência integrada a aspectos do mundo real e a problemáticas significativas.

Um estudo anterior desenvolvido por essa equipe de pesquisadores (GONÇALVES; DIAS; PERALTA, 2015) aponta que essa conexão talvez não seja tão óbvia ou que não se realize 
na prática. 0 estudo, que investigou as concepções de professores de educação profissional sobre a interdisciplinaridade no ensino de Matemática de cursos técnicos, sugeriu que não só aspectos estruturais tenham sido identificados pelos professores como um óbice a tais conexões, mas também que alguns destes adotavam uma concepção funcionalista de interdisciplinaridade. Encarando a interdisciplinaridade como condição e consequência básicas para a contextualização da Matemática em situações-problema do mundo real em sala de aula, esses resultados levaram os pesquisadores a perceber que há várias limitações para as devidas articulações necessárias para tal contextualização.

No contexto estadunidense, Meeder e Suddreth (2012) afirmam que, mesmo em lugares onde há integração de conteúdo acadêmico nos cursos de Carrer and Technical Education (CTE), a integração de conteúdo do mundo real no ensino das matérias acadêmicas do curso é quase inexistente. Os pesquisadores colocam ainda que projetos que permitissem a criação de conexões curriculares entre CTE e disciplinas acadêmicas requeriam que professores das diversas áreas revisassem seus parâmetros de conteúdo coletivamente, procurando oportunidades de integração e alinhamento entre esses conteúdos. Essa colocação é análoga às articuladas pelos professores no estudo feito em São Paulo pelos presentes pesquisadores, como mencionado (GONÇALVES; DIAS; PERALTA, 2015).

Buscando subsídios para a compreensão da relação entre ensino da Matemática e educação profissional na literatura estadunidense, não pudemos deixar de notar um esforço em avaliar como a participação em cursos de CTE se refletia nas matrículas e graduações em disciplinas da área de exatas, em particular a Matemática, em cursos superiores. Essa constatação nos levou a identificar uma diferença básica entre o caso estadunidense e o caso brasileiro. A referida preocupação vem do fato de o objetivo da CTE naquele país ter duplo aspecto: preparar alunos para carreiras e para a educação em nível superior. Identificamos esse ethos como um diferencial entre os dois casos, posto que, ainda que na educação profissional haja um componente acadêmico do currículo, o maior objetivo desse segmento de ensino é preparar para as exigências do mercado de trabalho.

Assim, propusemos um projeto de pesquisa interinstitucional - Universidade Estadual Paulista "Júlio de Mesquita Filho" (UNESP/ Brasil) e Central Michigan University (CMU/ EUA) - intitulado Estudo comparativo sobre o ensino de matemática em currículos de educação profissional técnica: Brasil e Estados Unidos, financiado pela Fundação de Amparo à Pesquisa de São Paulo (Fapesp), cujo objetivos foram: a) analisar semelhanças e singularidades da organização dos sistemas de ensino brasileiro e estadunidense, bem como seus marcos legais e arcabouços curriculares, ressaltando as possíveis orientações específicas sobre o ensino de Matemática na formação laboral; b) analisar semelhanças e singularidades inerentes às necessidades, dificuldades e estratégias de formação matemática presentes na formação profissional no contexto dos cursos da área da indústria das instituições pesquisadas (GONÇALVES; DIAS; PERALTA, 2018).

Como parte do referido projeto, elaboramos o presente artigo com o intuito de, a partir da caracterização da Educação Profissional e Tecnológica no sistema educacional brasileiro, discutir necessidades, dificuldades e estratégias didáticas apresentadas por professores brasileiros sobre a Matemática em cursos técnicos da área de indústria de uma escola pública do Brasil.

Para tanto, nossas análises assentaram-se nos seguintes procedimentos metodológicos: observações realizadas na escola (três visitas); análises documentais de currículos oficiais - Diretrizes Curriculares Nacionais para Educação Profissional Técnica de Nível Médio (BRASIL, 2012a); Catálogo Nacional de Cursos Técnicos (BRASIL, 2012b); Diretrizes Paulista de Educação Profissional (SÃO PAULO, 2000, 
2010, 2011); entrevistas semiestruturadas com professores de curso técnicos - realizadas no dia 18 de abril de 2016. Visto que nosso foco de investigação eram os cursos da área de indústria, selecionamos três professores, sendo um deles ex-coordenador de curso. Definimos como critério para seleção dos professores participantes da pesquisa: aceitar participar da investigação, ser professor (Matemática ou disciplinas técnicas) e/ou coordenador pedagógico de cursos da área da indústria. Salientamos que os cursos investigados não dispõem de professores específicos de Matemática. Segue o perfil dos professores investigados (os nomes apresentados são fictícios):

Ronaldo - engenheiro eletricista; mestrando em engenharia elétrica; não possui formação pedagógica para atuar em cursos técnicos; possui experiência docente de dois anos na profissional, além de experiência na área comercial/industrial como profissional técnico; atuou nos cursos Técnico em Mecânica e Técnico em Eletrotécnica.

André - engenheiro eletricista e de segurança do trabalho; mestrado incompleto em Engenharia Elétrica; possui formação pedagógica para atuar em cursos técnicos; atuou como coordenador pedagógico do curso Técnico em Eletrotécnica; possui 13 anos de experiência como docente em cursos técnicos; tem experiência como engenheiro eletricista; atuou como docente nos cursos Técnico em Eletrotécnica e Técnico em Segurança do Trabalho.

Carla - engenheira de controle e automação; mestranda engenharia mecânica; participação da formação pedagógica para atuar em cursos técnicos; possui dois anos de experiência docente em cursos técnicos - atuando nos cursos Técnico em Eletrotécnica e Técnico em Mecânica; não possui experiência na área comercial/ industrial como engenheira.

Ressaltamos que os supramencionados procedimentos são parte de uma metodologia substanciada em princípios da Educação Comparada de Ferrer Juliá (2002) e Pilz (2012). Ou seja, trata-se de um estudo comparativo de duas instituições de educação profissional (brasileira e estadunidense) visando com- preender a emergência desses contextos formativos. No âmbito brasileiro está sendo feita uma análise da organização e desenvolvimento curricular de uma escola pública paulista de educação profissional técnica e, no âmbito estadunidense, uma análise semelhante está sendo realizada em uma escola pública de educação profissional (CTE) do Estado de Michigan.

No Brasil, a pesquisa ocorreu em uma escola da rede pública estadual, localizada no interior do estado de São Paulo. A escola investigada foi fundada em 1993 e encontra-se vinculada à rede paulista de educação profissional (Centro Paula Souza). A escola investigada oferece os seguintes cursos: Ensino Médio; Técnico em Informática para Internet Integrado ao Ensino Médio; Técnico em Logística (subsequentes ou concomitantes); Técnico em Eletrotécnica (subsequentes ou concomitantes); Técnico em Meio Ambiente (subsequentes ou concomitantes); Técnico em Eventos (subsequentes ou concomitantes); Técnico em Serviços Jurídicos (subsequentes ou concomitantes); Técnico em Administração (subsequentes ou concomitantes); Técnico em Enfermagem (subsequentes ou concomitantes); Técnico em Mecânica (subsequentes ou concomitantes); Técnico em Eletrotécnica (subsequentes ou concomitantes). Na investigação optamos por tratar dos dois últimos.

\section{Organização da Educação Profissional no Brasil}

O censo escolar brasileiro de 2013 aponta que as matrículas na Educação Profissional cresceram $84,1 \%$ entre 2007 e 2013 . Ou seja, em 2013, o Brasil apresentava 1.441.051 de jovens na educação profissional, enquanto em 2007 somava 780.162. No mesmo período, o ensino público, em específico da Rede Federal de Educação Profissional, Científica e Tecnológica (RFEPCT), passou de 109.777 alunos para 228.427, o que representa um crescimento de 108\% (INSTITUTO NACIONAL DE PESQUISAS 
EDUCACIONAIS ANÍSIO TEIXEIRA, 2013). Tais matrículas são dispostas em escolas vinculadas aos sistemas de ensino: públicos (redes estaduais ou federal) e privado (rede de escolas particulares). Ressaltamos que a rede pública é organizada em três esferas: federal (gestão do governo federal), estadual (gestão dos governos dos estados) e municipal (gestão dos governos municipais) - em geral, conforme estabelecido na Constituição Federal, as redes municipais são responsáveis pela educação infantil e ensino fundamental.

A educação brasileira é organizada pela Lei no 9.394, de 20 de dezembro de 1996 - Lei de Diretrizes e Base da Educação Nacional (LDB), a qual estrutura o sistema de ensino em Educação Básica e Educação Superior (BRASIL, 1996).

A Educação Básica é composta pelos seguintes seguimentos: Educação Infantil (creche - crianças até três anos; pré-escola - crianças de quatro a cinco anos); Ensino Fundamental (nove anos de duração) e Ensino Médio (com duração mínima de três anos). A LDB normatiza ainda a Educação de Jovens e Adultos (EJA) como modalidade de Ensino da Educação Básica, destinada àqueles que não tiveram acesso ou continuidade de estudos no ensino fundamental e médio na idade própria, devendo articular-se, preferencialmente, com a Educação Profissional.

A Educação Superior é composta pelos seguintes cursos e programas: a) Cursos sequenciais por campo de saber - de diferentes níveis de abrangência, abertos a candidatos que atendam aos requisitos estabelecidos pelas instituições de ensino, desde que tenham concluído o Ensino Médio ou equivalente; b) Graduação - abertos a candidatos que tenham concluído o Ensino Médio ou equivalente e tenham sido classificados em processo seletivo; c) Pós-graduação - compreendendo programas de stricto sensu (mestrados acadêmicos ou profissionais e doutorados) e cursos de lato sensu (especialização, aperfeiçoamento e outros), abertos a candidatos diplomados em cursos de graduação; d) Extensão - abertos a candidatos que atendam aos requisitos, estabelecidos em cada caso, pelas instituições de ensino.

A Educação Profissional e Tecnológica (EPT) brasileira integra-se aos diferentes níveis e modalidades de educação e às dimensões do trabalho, da ciência e da tecnologia. A EPT se organizará por eixos tecnológicos e abrangerá os seguintes cursos: Formação Inicial e Continuada (FIC) ou Qualificação Profissional; Educação Profissional Técnica de Nível Médio (EPTNM); Educação Profissional Tecnológica (graduação e pós-graduação). A Resolução CNE/CEB no 6 (BRASIL, 2012a), fundamentada no Parecer CNE/CEB no 11 (BRASIL, 2012c), define as Diretrizes Curriculares Nacionais para o EPTNM.

No âmbito federal temos a Rede Federal de Educação Profissional, Científica e Tecnológica (RFEPCT), existente desde 1909, composta por: a) Institutos federais de educação, ciência e tecnologia (38 Institutos Federais espalhados em todos os estados brasileiros e no Distrito Federal); b) Universidade Tecnológica Federal do Paraná (UTFPR); c) Centro Federal de Educação Tecnológica Celso Suckow da Fonseca (CEFET/ RJ) e Centro Federal de Educação Tecnológica de Minas Gerais (CEFET/MG); d) Escolas técnicas vinculadas às universidades federais; e) Colégio Pedro II (GONÇALVES, 2012). Tais instituições oferecem cursos de EPT articulados aos diversos níveis e modalidades de ensino.

No estado de São Paulo, sítio de nossa investigação, a rede de educação profissional é formada pelo Centro Estadual de Educação Tecnológica Paula Souza (CEETEPS ou Centro Paula Souza), entidade autárquica do Estado de São Paulo, constituído a partir da experiência dos colégios técnicos profissionalizantes (industriais, agropecuários e serviços) existentes no estado de São Paulo (século XX). Passos (2006) afirma que o CEETEPS nasce da necessidade de constituir um núcleo de formação que acompanhasse o desenvolvimento industrial paulista. Nesse contexto, destacamos que o CEETEPS é vinculado à Secretaria de Desenvolvimento 
Econômico, Ciência, Tecnologia e Inovação do Estado de São Paulo, e não à Secretaria de Educação, subsidiando estrategicamente a Rede Estadual Paulista de Educação Profissional ao desenvolvimento econômico paulista. Atualmente, a rede estadual do CEETEPS (CENTRO PAULA SOUZA, 2015) é composta por 218 Escolas Técnicas Estaduais (Etec) e 63 Faculdades de Tecnologia (Fatec), reunindo mais de 283 mil alunos em cursos profissionalizantes (técnico e superior - tecnológicos), em mais de 300 municípios paulistas. As Etec atendem $212 \mathrm{mil}$ estudantes nos Ensinos Técnico, Médio e Técnico Integrado ao Médio, com 135 cursos técnicos para os setores industrial, agropecuário e de serviços, incluindo habilitações na modalidade semipresencial, Educação de Jovens e Adultos (EJA) e especialização técnica. Já nas Fatec mais de 70 mil alunos estão matriculados em 71 cursos de graduação tecnológica, em diversas áreas profissionais. Além da graduação (cursos tecnólogos), são oferecidos cursos de pós-graduação, atualização tecnológica e extensão.

Dentre as diversas escolas brasileiras que ofertam a Educação Profissional Técnica de Nível Médio (EPTNM) - com ou sem fins lucrativos -, chamamos a atenção para algumas escolas que se caracterizam como entidades ligadas diretamente aos setores produtivos, chamadas "Sistema S" (Sesi, Sesc, Senai, Senac, Senar, Sebrae, previstas pela Constituição Federal brasileira no seu artigo 149). Tais escolas são subsidiadas pelo próprio setor produtivo por meio de impostos e seus currículos são construídos em articulação com o setor produtivo (empresas e sindicatos), a partir de demandas reais do "mercado de trabalho", gerando altos índices de empregabilidade dos egressos dos cursos.

Conforme disposto nas Diretrizes Curriculares Nacionais para a EPTNM (BRASIL, 2012a), tais cursos têm por finalidade proporcionar ao estudante conhecimentos, saberes e competências profissionais necessários ao exercício profissional e da cidadania, com base nos fundamentos científico-tecnológicos, sócio-histó- ricos e culturais (BRASIL, 2012a), visando ao exercício de profissões técnicas.

A EPTNM será desenvolvida nas formas articulada e subsequente ao Ensino Médio:

Articulada é desenvolvida nas seguintes formas: a) Integrada - ofertada somente a quem já tenha concluído o Ensino Fundamental, com matrícula única na mesma instituição, de modo a conduzir o estudante à habilitação profissional técnica de nível médio ao mesmo tempo em que concluam a última etapa da Educação Básica; b) Concomitante - ofertada aos ingressantes no Ensino Médio (ou já o estejam cursando), efetuando-se matrículas distintas para cada curso, aproveitando oportunidades educacionais disponíveis, seja em unidades de ensino da mesma instituição ou em distintas instituições de ensino; c) Concomitante na forma - é desenvolvida simultaneamente em distintas instituições educacionais, mas integrada no conteúdo, mediante a ação de convênio ou acordo de intercomplementaridade, para a execução de projeto pedagógico unificado.

Subsequente é desenvolvida em cursos destinados exclusivamente a quem já tenha concluído o Ensino Médio.

Quanto à organização curricular, as Diretrizes Curriculares Nacionais (BRASIL, 2012a) estabelecem que os cursos de EPTNM devam ser organizados por eixos tecnológicos constantes do Catálogo Nacional de Cursos Técnicos (CNCT) (BRASIL, 2012b). Tal catálogo deve ser organizado tomando como referência a Classificação Brasileira de Ocupações (CBO) ${ }^{1}$ (BRASIL, 2002). No entanto, pode também ser critério para a organização curricular a identificação de perfil profissional de conclusão próprio para cada curso. Os 13 eixos tecnológicos, definidos pelo CNCT (BRASIL, 2012b), são: Ambiente e Saúde; Controle e Processos Industriais; Desenvolvimento Educacional e Social; Informação e Comunicação; Infraestrutura; Gestão e Negócios; Militar; Produção Cultural e Design; Produção Alimentícia; Produção Industrial; Turismo, Hospitalidade e Lazer; Recursos Naturais; Segu-

1 Tem por finalidade a identificação das ocupações no mercado de trabalho brasileiro, para fins classificatórios junto aos registros administrativos e domiciliares. 
rança. No detalhamento das características de cada curso técnico, o CNCT dispõe sobre a carga horária mínima exigida por curso, na ordem de 800 horas, 1.000 horas e 1.200 horas.
A carga horária mínima de cada curso da EPTNM é indicada no CNCT, segundo cada habilitação profissional - conforme os Quadros 1 e 2 .

Quadro 1 - Carga horária da EPTNM na forma articulada integrada

\begin{tabular}{|c|c|c|}
\hline Forma & Oferta & Horas \\
\hline \multirow{3}{*}{$\begin{array}{l}\text { ARTICULADA / } \\
\text { INTEGRADA }\end{array}$} & $\begin{array}{l}\text { Integrada com o Ensino Médio } \\
\text { regularmente oferecido, na idade } \\
\text { própria, no mesmo estabelecimen- } \\
\text { to de ensino. }\end{array}$ & $\begin{array}{l}\text { Mínimo de } 3.000,3.100 \text { ou } 3.200 \text { horas, para a } \\
\text { escola e para o estudante, conforme a habilita- } \\
\text { ção profissional ofertada. }\end{array}$ \\
\hline & $\begin{array}{l}\text { Integrada com o Ensino Médio na } \\
\text { modalidade de Educação de Jovens } \\
\text { e Adultos (EJA), no mesmo estabe- } \\
\text { lecimento de ensino. }\end{array}$ & $\begin{array}{l}\text { Mínimos de } 800,1.000 \text { ou } 1.200 \text { horas, confor- } \\
\text { me a habilitação profissional ofertada, acresci- } \\
\text { da de mais } 1.200 \text { horas destinadas à parte da } \\
\text { formação geral, totalizando mínimos de } 2.000 \text {, } \\
2.200 \text { ou } 2.400 \text { horas para a escola e para o es- } \\
\text { tudante. }\end{array}$ \\
\hline & $\begin{array}{l}\text { Integrada com o Ensino Médio } \\
\text { no âmbito do PROEJA }{ }^{2} \text { (BRASIL, } \\
\text { 2006). }\end{array}$ & $\begin{array}{l}\text { Mínimos de } 800,1.000 \text { ou } 1.200 \text { horas, confor- } \\
\text { me a habilitação profissional ofertada, acresci- } \\
\text { das de mais } 1.200 \text { horas para a formação geral, } \\
\text { devendo sempre totalizar } 2.400 \text { horas, para a } \\
\text { escola e para o estudante. }\end{array}$ \\
\hline
\end{tabular}

Fonte: Parecer CNE/CEB no 11 (BRASIL, 2012c).

Quadro 2 - Carga horária da EPTNM nas formas articulada concomitante e subsequente

\begin{tabular}{|c|l|l|}
\hline \multicolumn{1}{|c|}{ Forma } & \multicolumn{1}{|c|}{ Oferta } & \multicolumn{1}{c|}{ Horas } \\
\hline \multirow{2}{*}{$\begin{array}{l}\text { ARTICULADA / } \\
\text { CONCOMITANTE }\end{array}$} & $\begin{array}{l}\text { Concomitante com o Ensino Mé- } \\
\text { dio regular, na mesma instituição } \\
\text { de ensino ou em instituições de } \\
\text { ensino distintas, aproveitando-se } \\
\text { as oportunidades educacionais } \\
\text { disponíveis. }\end{array}$ & $\begin{array}{l}\text { Mínimos de 800, 1.000 ou 1.200 horas, confor- } \\
\text { me habilitação profissional ofertada, na insti- } \\
\text { tuição de Educação Profissional e Tecnológica, } \\
\text { acrescida de mais 2.400 horas na unidade esco- } \\
\text { lar de Ensino Médio, totalizando os mínimos de } \\
3.200,3.400 \text { ou 3.600 horas para o estudante. }\end{array}$ \\
\cline { 2 - 4 } & $\begin{array}{l}\text { Concomitante com o Ensino } \\
\text { Médio na modalidade de EJA, na } \\
\text { mesma instituição de ensino ou } \\
\text { em instituições de ensino distin- } \\
\text { tas aproveitando-se as oportuni- } \\
\text { dades educacionais disponíveis. }\end{array}$ & $\begin{array}{l}\text { Mínimos de 800, 1.000 ou 1.200 horas, confor- } \\
\text { me habilitação profissional ofertada, na insti- } \\
\text { tuiça de Educação Profissional e Tecnológica, } \\
\text { acrescidas de mais 1.200 horas na unidade es- } \\
\text { colar de Ensino Médio na modalidade de EJA, } \\
\text { totalizando 2.000, 2.200 ou 2.400 horas para o } \\
\text { estudante. }\end{array}$ \\
\hline \multirow{2}{*}{ SUBSEQUENTE } & $\begin{array}{l}\text { Educação Profissional Técnica de } \\
\text { Nível Médio ofertada após a con- } \\
\text { clusão do Ensino Médio regular } \\
\text { ou na modalidade de EJA. }\end{array}$ & $\begin{array}{l}\text { Mínimos de 800, 1.000 ou 1.200 horas para o } \\
\text { estudante, conforme habilitação profissional } \\
\text { ofertada na Instituição de Educação Profissio- } \\
\text { nal e Tecnológica. }\end{array}$ \\
\hline
\end{tabular}

Fonte: Parecer CNE/CEB no 11/2012 (BRASIL, 2012c).

2 Institui, no âmbito federal, o Programa Nacional de Integração da Educação Profissional com a Educação Básica na Modalidade de Educação de Jovens e Adultos (Proeja), cujo objetivo era a oferta de cursos e programas de Educação Profissional destinados à formação inicial e continuada de trabalhadores e à EPTNM. 
No estado de São Paulo, o aproveitamento de estudos e de experiências anteriores, em cursos técnicos, é condicionado ao perfil profissional de conclusão pretendida. Em tal aproveitamento poderão ser considerados conhecimentos e experiências anteriores, no todo ou em parte, desde que diretamente relacionados com o perfil profissional de conclusão da respectiva qualificação, especialização ou habilitação profissional, adquiridos: a) no ensino médio; b) em qualificações profissionais e etapas ou módulos de nível técnico concluídos em outros cursos desse nível; c) em cursos de Educação Profissional de nível básico, mediante avaliação do aluno pela escola; d) no trabalho ou por outros meios informais, mediante avaliação do aluno pela escola; e) e reconhecidos em processos formais de certificação profissional (SÃO PAULO, 2000).

Em consonância com as Diretrizes Nacionais da EPTNM, o Estado de São Paulo estabelece que estão habilitados para a docência na Educação Profissional de Nível Técnico os profissionais licenciados (licenciatura plena ou programa especial de formação) na área profissional objeto do curso e no correspondente componente curricular. Na falta de profissionais com licenciatura específica e experiência profissional comprovada na área objeto do curso, o estabelecimento de ensino deverá propiciar formação em serviço, apresentando, para tanto, plano especial de preparação de docentes ao respectivo órgão supervisor (SÃO PAULO, 2000).

Os documentos analisados ${ }^{3}$ não fazem referências específicas ao ensino de Matemática na EPTNM, todavia estabelecem que as Diretrizes Nacionais para EPTNM discorrem, nos princípios norteadores do EPTNM, que a interdisciplinaridade deve ser assegurada no currículo e na prática pedagógica, visando à superação da fragmentação de conhecimentos

3 Diretrizes Curriculares Nacionais para Educação Profissional Técnica de Nível Médio (BRASIL, 2012a); Catálogo Nacional de Cursos Técnicos (BRASIL, 2012b); Diretrizes Paulista de Educação Profissional (SÃO PAULO, 2000, 2010, 2011). e de segmentação da organização curricular. Além da contextualização e da flexibilidade, a interdisciplinaridade deverá ser utilizada como estratégia educacional favorável à compreensão de significados e à integração entre a teoria e a vivência da prática profissional, envolvendo as múltiplas dimensões do eixo tecnológico do curso e das ciências e tecnologias a ele vinculadas. As Diretrizes Curriculares Nacionais para Educação Profissional Técnica de Nível Médio (BRASIL, 2012a) definem o "trabalho" como princípio educativo da EPTNM, tendo sua integração com a ciência, a tecnologia e a cultura.

\section{Organização e Desenvolvimento Curricular da Escola Investigada}

Discutiremos os dados produzidos em nossa investigação com base em duas categorias de análise e interpretação: Planejamento Curricular e Currículo de Matemática. Salientamos que tais categorias estão posicionadas na realidade em que os dados foram produzidos - escola, cursos e professores investigados.

\section{Planejamento Curricular}

Nas escolas técnicas do Centro Paula Souza os currículos dos cursos são planificados de forma unificada para todas as escolas técnicas estaduais paulistas. Nesse processo são reunidos no Laboratório de Currículos profissionais da área, docentes, especialistas, supervisão educacional para estudo do material produzido pela Classificação Brasileira de Ocupações (CBO), do CNCT e para análise das necessidades do mercado de trabalho, assim como o Catálogo Nacional de Cursos Técnicos. Após uma sequência de encontros de trabalho, é organizado o currículo dos cursos.

Após a planificação dos Planos de Curso no Laboratório de Currículo, o seu processo de implementação ocorre por meio de reunião 
pedagógica com os coordenadores de curso das diversas escolas da rede, em que é apresentada a organização curricular do curso. Os referidos coordenadores, a partir das informações obtidas nessas reuniões, retornam a suas escolas para desenvolverem os currículos. Em entrevista, o Professor André acrescenta:

Eu nunca participei direto, pois ocorre lá em São Paulo, existe lá uma equipe de pessoas que é chamado de grupo de atualização de currículo, então cada curso tem a sua equipe, então o eletrotécnico, existe um grupo de professores que saíram da sala de aula e através um concurso interno assumiram essa função pra cuidar do currículo, eles gerenciam o currículo, então a cada cinco ou seis anos ocorre a atualização do currículo, então tem essa equipe que fica lá pra fazer isso, então cada curso tem a sua equipe, eletrotécnico, mecânica, enfermagem, tem as equipes que estão lá pra fazer essa atualização, quando eu fui coordenador, por quatro anos, eu cheguei a participar de reuniões, mas as reuniões eram só uma apresentação, eles apresentavam o que mudou, quais eram as novidades, 0 que foi pensado pra fazer a nova estrutura. Eu já estive em São Paulo [capital] em reuniões para fazer isso, mas é um pessoal que já chega com tudo pronto, não tem aquilo de vamos discutir juntos, mas é legal, tem atendido bem o mercado. (ANDRÉ, 13 anos de experiência docente na EPT, 2016).

Assim, a estrutura mostra uma verticalidade no processo de construção curricular, obedecendo uma dita lógica de "maximização do trabalho docente". Acreditamos que isso possa promover um processo efetivo de constituição das competências profissionais previstas nos planos de curso; todavia, os professores revelaram distanciamentos de tais processos de planejamento curricular, situação que julgamos comprometer a previsão de necessidades formativas oriundas de certas localidades, mas que possam vir a se constituir como demandas futuras em outras regiões de atuação do profissional técnico.

Avançando na análise, a partir de uma perspectiva filosófica e sociológica da escola como espaço público e democrático, evidenciamos a necessidade de construção do currículo a partir do Agir Comunicativo (HABERMAS, 2003) em que sujeitos se protagonizem nas diversas esferas de construção desse currículo. Desse modo, esses profissionais poderiam transcender aspectos que comprometem a autonomia profissional docente e que caracterizam professores como meros executores do currículo, promotores de uma racionalidade instrumental na sua ação docente, deslegitimando um processo crítico de profissionalidade. Logo, consubstanciamo-nos em Jügen Habermas, expoente da segunda geração da Escola de Frankfurt e crítico da racionalidade que orienta as relações sociais, para compreender o cenário das escolas profissionalizantes.

Na medida em que os atores estão exclusivamente orientados para o sucesso, isto é, para as consequências do seu agir, eles tentam alcançar os objetivos de sua ação influindo externamente, por meio de armas ou bens, ameaças ou seduções, sobre a definição da situação ou sobre as decisões ou motivos de seus adversários. A coordenação das ações de sujeitos que se relacionam dessa maneira, isto é, estrategicamente, depende da maneira como se entrosam os cálculos de ganho egocêntricos. 0 grau de cooperação e estabilidade resulta então das faixas de interesses dos participantes. Ao contrário, falo em agir comunicativo quando os atores tratam de harmonizar internamente seus planos de ação e de só perseguir suas respectivas metas sob a condição de um acordo existente ou a se negociar sobre a situação e as consequências esperadas (HABERMAS, 2003).

O Plano de Curso é um documento normativo e prescrito em que são definidos: objetivos e justificativa do curso; requisitos de acesso; perfil profissional do egresso; organização curricular; critérios de aproveitamento de conhecimentos e experiências anteriores; critérios de avaliação da aprendizagem; instalações e equipamentos; pessoal docente e técnico; certificados e diplomas. A partir do Plano de Curso, os professores 
elaboram o seu Plano de Trabalho Docente (PTD), construído por componente curricular; tal documento estabelece - alinhado com as Competências, Habilidades e Bases Tecnológicas definidas no Plano de Curso - os procedimentos didáticos de acordo com os dias de cada aula. Assim, a necessidade de construção do referido PTD faz com que os professores tenham conhecimento dos Planos de Curso. Entretanto, reafirmamos que acreditamos ser necessário o envolvimento desses professores no processo de construção desses planos, fazendo-os reconhecer sua profissionalidade.

[...] a gente tem um projeto básico que o Centro manda pra gente. Aí nesse projeto básico constam todas as competências que devem ser desenvolvidas pra todas as disciplinas, toda a estruturação do curso não é a gente que faz, vem já do Centro Paula Souza. Se você quiser eu posso até te mandar esse arquivo, com toda a nossa estrutura do eletrotécnico, com todas as atribuições, que tem que ser, o que o professor faz. Cada professor pega e monta seu plano de curso. 0 meu plano de aula é montado em cima das atribuições que o centro manda, então vem meio que de cima pra baixo. Eles elaboram todo um projeto pra poder uniformizar, apesar das aulas não serem exatamente as mesmas, mas a mesma estrutura que eu sigo aqui é seguida [...] [em outra ETEC], em qualquer uma delas, segue a mesma estrutura de curso e os professores pegam aquela estrutura básica e montam seu plano de aula a partir daquilo. (ANDRÉ, 13 anos de experiência docente na EPT, 2016).

No processo de elaboração desse PTD, os professores dispõem de criatividade, a partir dos conteúdos já instituídos para organizar sua aula:

[...] eles chamam de PTD, que todo semestre temos que montar nosso plano de trabalho ao longo do semestre, com base nas diretrizes que o Centro nos passa, que é o conteúdo mínimo que temos que ministrar para os alunos, dando uma flexibilidade, para passar conteúdos a mais ou a menos dependendo da dificuldade de equipamentos no laboratório. (RONALDO, 2 anos de experiência docente na EPT, 2016).
Assim, no PTD o professor viabiliza perspectivas curriculares interdisciplinares e contextualizadas com o mundo do trabalho a partir de sua interface com as demandas locais da região de oferta do curso; todavia, conforme provocado anteriormente, tais demandas poderiam ser potencializadas durante o processo de planificação dos referidos currículos, situação que não identificamos na presente investigação.

Portanto, faz-se presente na elaboração do PDT a preocupação com as demandas locais no curso, conforme aponta André durante a entrevista:

Ele pode ter um detalhe ou outro focado meio diferente por causa da região, mas o conteúdo vai ser o mesmo, por exemplo, em máquinas agora estou trabalhando a parte de geração, então fala muito de hidrelétrica, porque é o nosso ramo aqui, mas em uma região que é mais sucroalcooleira, pode falar mais de cogeração, mas vai falar de geração a mesma coisa, muda um pouquinho só aquele foco, mas esse é um dos objetivos que o Centro [Paula Souza] coloca como premissa, para se concentrar na área de atuação do seu aluno. Por exemplo, se ele vai trabalhar numa região, igual aqui, nós trabalhamos muito com hidrelétrica, [...] [pois] estamos em um polo de hidrelétricas, então a gente foca mais nessa área. (ANDRÉ, 13 anos de experiência docente na EPT, 2016).

As aulas dispostas no PTD são organizadas semanalmente e, após aprovadas pelo coordenador do curso, são registradas no sistema acadêmico, em que o professor, os alunos e os coordenadores têm acesso aos conteúdos e atividades de cada dia. Quaisquer necessidades de realinhamento das aulas devem ser solicitadas ao coordenador do curso, que alterará no sistema acadêmico.

Nosso plano tem semanalmente o que vai ser trabalhado e tem espaço para realinhamento, caso eu não consiga trabalhar, replaneja para próxima semana. 0 coordenador que ajusta o realinhamento e faz o acompanhamento para ver se as disciplinas estão sendo trabalhadas de acordo, [...] isso é feito no papel e é entregue para o coordenador quando o realimento é necessário. (ANDRÉ, 13 anos de experiência docente na EPT, 2016). 
[...] e tem o realinhamento do trabalho docente que quando estou em um conteúdo e eu acho que a sala tem dificuldade em algum conteúdo e vou acabar demorando mais, ou quando uma sala não tem dificuldade e posso acelerar certo conteúdo, então podemos fazer um realinhamento no sistema do professor, que vai para a avaliação do coordenador de curso para aprovação. (CARLA, dois anos de experiência docente na EPT, 2016).

Acreditamos que a previsão da flexibilização - eixo da EPT nas diretrizes curriculares (BRASIL, 2012a) - ainda é incipiente, pois denota pensar trajetórias formativas que promovam escolhas aos alunos relativas ao mundo do trabalho, e não apenas escolhas feitas pelo professor a partir das demandas locais.

Ressaltamos que tal lógica de flexibilização possa conceber trajetórias formativas que perpassem um desenvolvimento curricular assentado no agir comunicativo diante da percepção interativa com o mundo do trabalho que supere uma lógica neoliberal, em que as escolhas sejam feitas além de elementos imediatistas de empregabilidade induzidos pelo mercado de trabalho, mas sim por decisões que possibilitem aos alunos constituir trajetórias formativas, vinculadas a carreiras, a partir de elementos filosóficos e sociais do trabalho.

Para o acompanhamento do desenvolvimento curricular, a escola investigada realiza reuniões pedagógicas.

O planejamento das aulas é feito no começo do semestre, antes das aulas começarem, e durante o semestre tem outras reuniões de planejamento e reuniões pedagógicas, e na primeira semana de aula nós recebemos o novo documento do plano de trabalho docente com as bases das disciplinas, e trabalhamos o conteúdo da disciplina e distribuímos ao longo do semestre. [...] As reuniões pedagógicas ocorrem três ou quatro vezes ao longo do semestre. (CARLA, dois anos de experiência docente na EPT, 2016).

Os professores revelaram que tais reuniões são fundamentais no processo de realinhamento dos PTD a partir da coletividade, promovendo avanços nas perspectivas interdisciplinares e de contextualização do desenvolvimento curricular. Entretanto, a partir das descrições que os professores fazem de tais reuniões, percebemos que o papel deles é de executores dos currículos, não tendo estes participação efetiva no processo de planejamento. Observamos ainda que os professores, inclusive os que possuem uma formação pedagógica, não constatam tal lógica de desenvolvimento curricular com estranheza.

A escola dispõe ainda do Plano Plurianual de Gestão (PPG), que de acordo com o próprio documento é construído de forma participativa e democrática, tendo vigência de cinco anos na escola investigada com vigência de 2015 a 2019. Tal documento caracteriza-se como plano de trabalho da escola, contando no seu bojo com o Projeto Político-Pedagógico (PPP), norteador do PPG e que deveria explicitar valores, crenças e princípios pedagógicos para a escola. Ao analisarmos tal documento da escola, em especial o seu PPP, o julgamos como administrativo institucional que não dispõe de natureza política e pedagógica. Pressupomos, substanciados em Gadotti (2000), que tal problemática possa a estar vinculada à mentalidade de atribuir aos técnicos a gestão de currículos, considerando os demais segmentos incapazes de exercer e participar de tal processo - estrutura verticalizada de nossos sistemas educacionais e o autoritarismo que, historicamente, tem impregnado o ethos educacional.

\section{Currículo de Matemática}

A pesquisa teve como um de seus objetivos caracterizar a Matemática no desenvolvimento curricular do contexto da EPT. Para tanto, traremos à tona contextos da realidade dos cursos técnicos em Mecânica e Eletrotécnica.

Os cursos investigados (Técnico em Eletrotécnica ${ }^{4}$ e Técnico em Mecânica ${ }^{5}$ ) têm duração de dois anos, possuem carga horária de 1.600 horas e se estruturam a partir de quatro módulos (conforme Figuras 1 e 2).

$\begin{array}{ll}4 & \text { Ver Centro Paula Souza (2001a). } \\ 5 & \text { Ver Centro Paula Souza (2001b). }\end{array}$ 
Figura 1 - Módulos do curso Técnico em Eletrotécnica

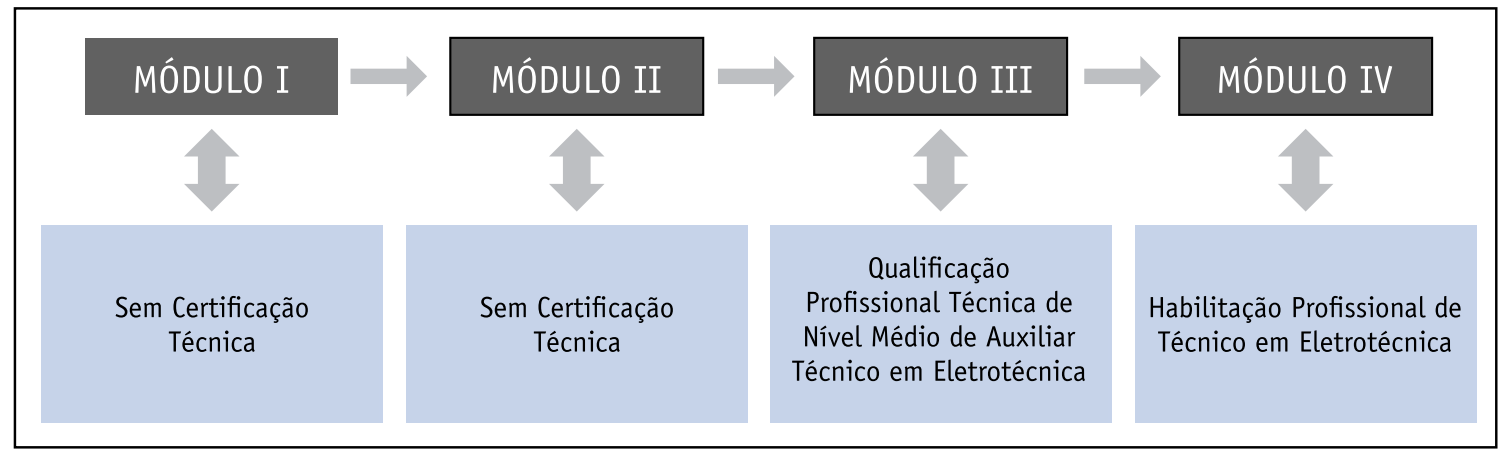

Fonte: Plano do Curso Técnico em Eletrotécnica (CENTRO PAULA SOUZA, 2001a, p. 12).

Figura 2 - Módulos do curso Técnico em Mecânica

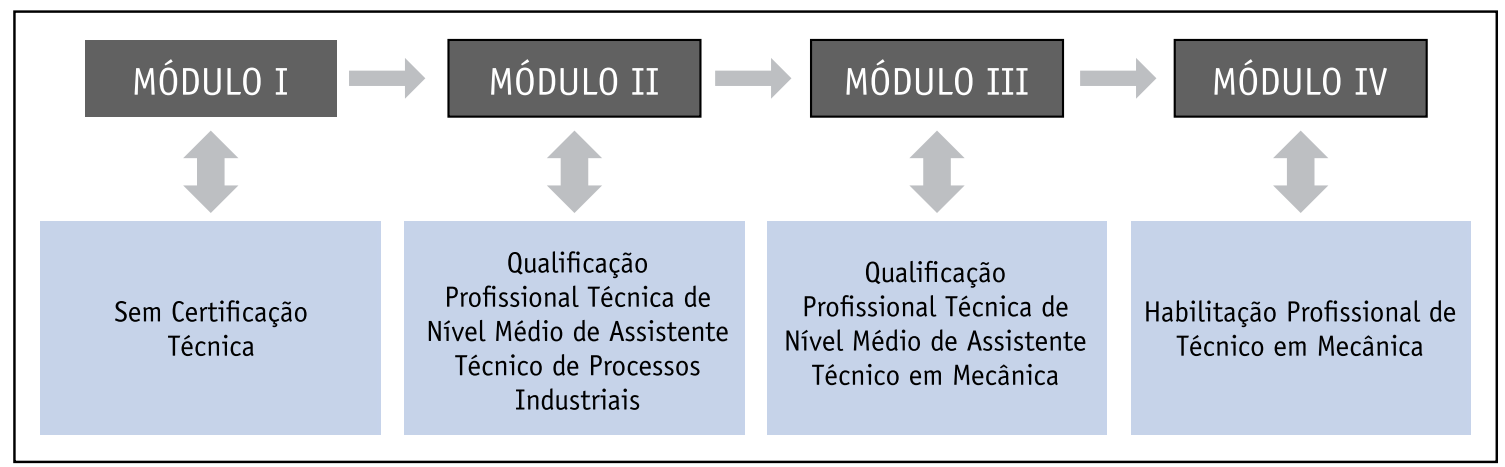

Fonte: Plano do Curso Técnico em Mecânica (CENTRO PAULA SOUZA, 2001b, p. 8).

Os planos de ensino são organizados por uma equipe de especialistas, conforme explicitado anteriormente, do/no Centro Paula Souza, e na escola tal currículo é implementado a partir do PTD. Assim, a formação do profissional técnico do Centro Paula Souza estrutura-se pela perspectiva competências e habilidades, ${ }^{6}$ ou seja, a partir da definição do perfil do profissional técnico estabelecem-se as competências necessárias para tal atuação, distribuindo-as nos diversos componentes curriculares do curso. A competência constitui-se a partir de uma série de habilidades subvencionadas por bases tecnológicas. ${ }^{7}$ A partir daí os professores planejam suas atividades docentes no PTD, estabelecendo os procedimentos didáticos do

6 Neste texto o uso da expressão competências e habilidades se dá em razão da forma como ela aparece nos documentos curriculares analisados nesta pesquisa, porém é de nosso entendimento a falta de consenso teórico em torno de tais termos.

7 Entendemos a expressão bases tecnológicas como bases científicas e tecnológicas, contudo optamos por utilizar o termo utilizado nos Planos de Curso. processo educativo que desencadeiem a formação do profissional técnico.

Nesse contexto, são as Bases Tecnológicas que garantirão a radicalidade na construção das habilidades e competências necessárias para a atuação do profissional técnico com a autonomia necessária para a tomada de decisões diante das adversidades presentes no mundo do trabalho.

Logo, centrados nessa perspectiva, identificamos na organização curricular do curso Técnico em Eletrotécnica, a partir da análise do seu plano de curso (CENTRO PAULA SOUZA, 2001a), a presença direta da Matemática nos seguintes componentes curriculares do $1^{\mathrm{o}}$ módulo: Eletrônica Digital I, Circuitos Elétricos I e Desenho Técnico (conforme detalhado nos Quadros 3 a 5). Os Quadros 3 a 8 foram construídos a partir de um recorte dos planos de curso e ressaltam apenas as competências que envolvem a Matemática. Os planos de ensino completos dos cursos analisados podem ser consultados nos sítios do Centro Paula Souza (2001a, 2001b). 
Quadro 3 - Recorte do plano de curso do componente curricular Eletrônica Digital I, evidenciando os elementos relacionados à Matemática

\begin{tabular}{|c|c|c|}
\hline \multicolumn{2}{|l|}{ DISCIPLINA: Eletrônica Digital I (50 horas-aulas - práticas) } \\
\hline \multicolumn{2}{|c|}{ FUNÇÃO: Planejamento e Controle na Manutenção } \\
\hline COMPEÊNCIA & \multicolumn{1}{|c|}{ HABILIDADES } & BASES TECNOLÓGICAS \\
$\begin{array}{l}\text { Analisar os principais sistemas } \\
\text { de numeração. }\end{array}$ & $\begin{array}{l}\text { Aplicar métodos de cálculos de } \\
\text { conversão entre sistemas de } \\
\text { numeração. }\end{array}$ & $\begin{array}{l}\text { Sistemas de numeração: } \\
\text { Binário; Decimal; Hexadecimal. }\end{array}$ \\
\hline
\end{tabular}

Fonte: Plano do Curso Técnico em Eletrotécnica (CENTRO PAULA SOUZA, 2001a).

Quadro 4 - Recorte do plano de curso do componente curricular Circuitos Elétricos I, evidenciando os elementos relacionados à Matemática

\begin{tabular}{|c|c|c|}
\hline \multicolumn{3}{|c|}{$\begin{array}{l}\text { DISCIPLINA: Circuitos Elétricos I (50 horas-aulas } \\
\text { FUNÇÃo: Manutenção dos Sistemas Industriais }\end{array}$} \\
\hline COMPETÊNCIA & HABILIDADES & BASES TECNOLÓGICAS \\
\hline $\begin{array}{l}\text { Interpretar conceitos } \\
\text { matemáticos e suas } \\
\text { aplicações. }\end{array}$ & $\begin{array}{l}\text { Identificar noções de } \\
\text { grandezas elétricas. } \\
\text { Identificar as funções } \\
\text { com o comportamento de } \\
\text { dispositivos discretos. } \\
\text { Identificar as funções } \\
\text { trigonométricas com } \\
\text { noções de defasagem: fator } \\
\text { de potência e correções de } \\
\text { fator de potência. }\end{array}$ & $\begin{array}{l}\text { Conceitos Matemáticos: } \\
\text { Números decimais; Prefixos numéricos } \\
\text { (nomenclatura e conversões); } \\
\text { Potência de Dez (definição e operações) > } \\
\text { notação científica; } \\
\text { Operações com frações e expressões } \\
\text { algébricas; } \\
\text { Multímetro e teoria dos erros; } \\
\text { Paquímetro e micrômetro; } \\
\text { Unidades de medida em eletrotécnica e } \\
\text { conversões; } \\
\text { Porcentagem: tolerância de resistência } \\
\text { elétrica em resistores; } \\
\text { Função de 1. grau (equações e gráficos): } \\
\text { lei de ohm; } \\
\text { Funções de } 2^{o} \text { grau: potência elétrica; } \\
\text { Função exponencial: comportamento de } \\
\text { diodos e transistores; } \\
\text { Função logarítmica: cálculo de bits de } \\
\text { endereçamento; } \\
\text { Matrizes: regras de Crammer e Sarrus; } \\
\text { aplicação em circuitos elétricos; } \\
\text { Relações trigonométricas: aplicação em } \\
\text { circuitos elétricos RLC; } \\
\text { Números complexos: aplicação em } \\
\text { circuitos elétricos de corrente alternada; } \\
\text { Operações: soma, subtração, multiplicação } \\
\text { e divisão; } \\
\text { Formas retangular e polar. }\end{array}$ \\
\hline
\end{tabular}

Fonte: Plano do Curso Técnico em Eletrotécnica (CENTRO PAULA SOUZA, 2001a). 
Quadro 5 - Recorte do plano de curso do componente curricular Desenho Técnico, evidenciando os elementos relacionados à Matemática

\begin{tabular}{|c|c|c|}
\hline \multicolumn{3}{|c|}{ FUNÇÃO: Planejamento da Produção } \\
\hline COMPETÊNCIA & HABILIDADES & BASES TECNOLÓGICAS \\
\hline $\begin{array}{l}\text { 1. Correlacionar as técnicas de } \\
\text { desenho e de representações } \\
\text { gráficas com seus fundamentos } \\
\text { matemáticos e geométricos, } \\
\text { visando sua interpretação. }\end{array}$ & $\begin{array}{l}\text { - Utilizar técnicas } \\
\text { específicas de desenho } \\
\text { técnico. } \\
\text { - Elaborar desenho técnico. }\end{array}$ & $\begin{array}{l}\text { Desenho Técnico: } \\
\Rightarrow \text { Normas padronizadas } \\
\Rightarrow \text { Instrumentos } \\
\Rightarrow \text { Caligrafia técnica } \\
\Rightarrow \text { Desenhogeométrico, } \\
\quad \text { escalas, cotas } \\
\Rightarrow \text { Projeções ortogonais } \\
\Rightarrow \text { Perspectivas } \\
\Rightarrow \text { Simbologia elétrica }\end{array}$ \\
\hline
\end{tabular}

Fonte: Plano do Curso Técnico em Eletrotécnica (CENTRO PAULA SOUZA, 2001a).

Na organização curricular do curso Técnico em Mecânica, a Matemática aparece diretamente nas seguintes disciplinas do primeiro mó- dulo: Fundamentos da Matemática e da Física Aplicados à Mecânica, Metrologia I e Desenho Técnico Mecânico (conforme Quadros 6 a 8).

Quadro 6 - Recorte do plano de curso do componente curricular Fundamentos da Matemática e da Física Aplicados à Mecânica, evidenciando os elementos relacionados à Matemática

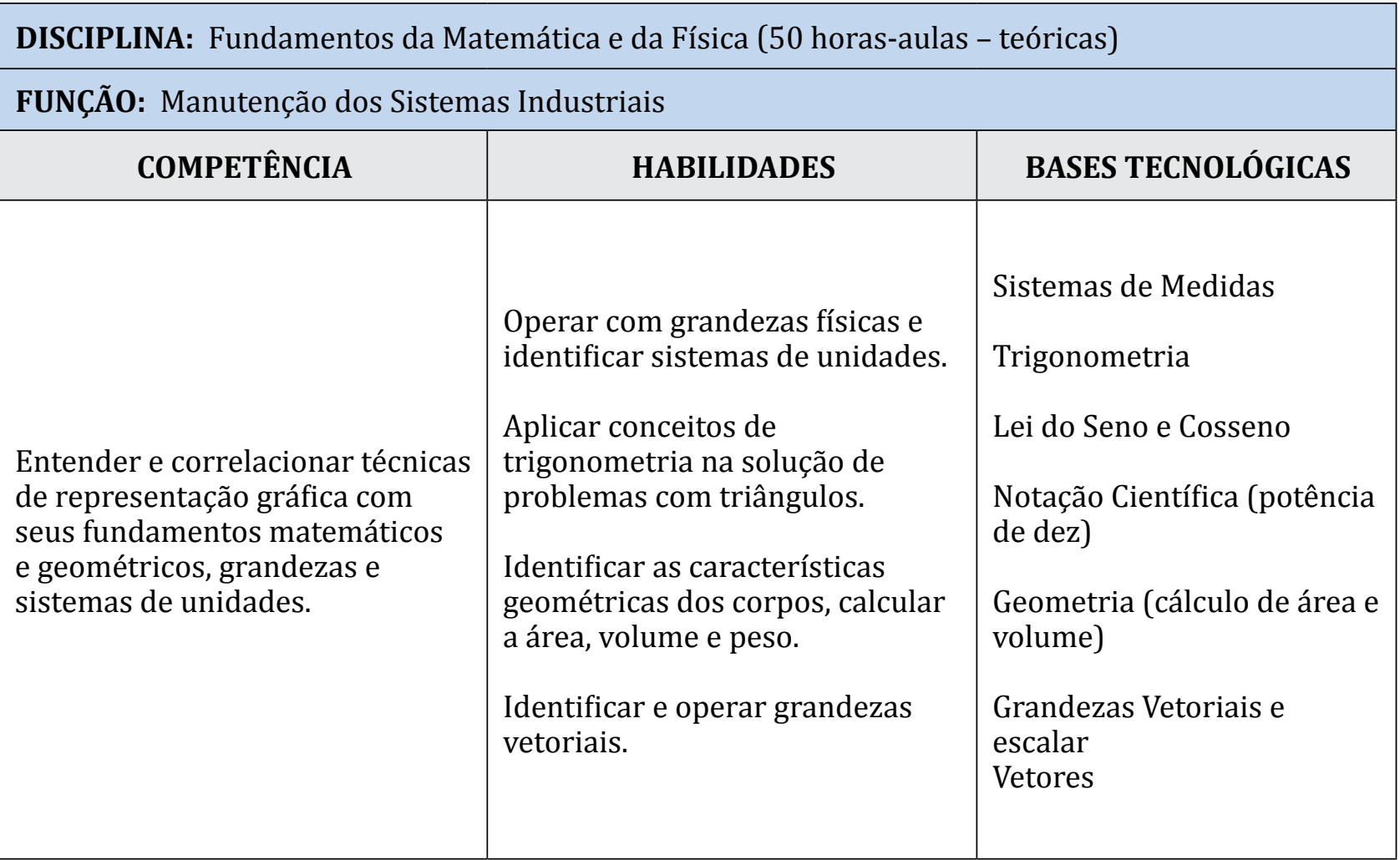

Fonte: Plano do Curso Técnico em Mecânica (CENTRO PAULA SOUZA, 2001b). 
Quadro 7 - Recorte do plano de curso do componente curricular Metrologia I, evidenciando os elementos relacionados à Matemática

\begin{tabular}{|c|c|c|}
\hline \multicolumn{3}{|c|}{ FUNÇÃO: Programação e Controle de Produção } \\
\hline COMPETÊNCIA & HABILIDADES & BASES TECNOLÓGICAS \\
\hline $\begin{array}{l}\text { Contextualizar fundamentos } \\
\text { matemáticos nas práticas } \\
\text { metrológicas. } \\
\text { Compreender grandezas } \\
\text { dimensionais em desenhos, } \\
\text { componentes e conjuntos mecânicos. } \\
\text { Identificar métodos de medição e } \\
\text { interpretações de suas leituras. }\end{array}$ & $\begin{array}{l}\text { Efetuar cálculos e } \\
\text { elaborar relatórios. } \\
\text { Interpretar elementos } \\
\text { que compõem projetos. } \\
\text { Medir componentes } \\
\text { que compõem projetos. } \\
\text { Manusear instrumentos } \\
\text { de medição. } \\
\text { Interpretar normas } \\
\text { técnicas pertinentes. }\end{array}$ & $\begin{array}{l}\text { Cálculos com frações. } \\
\text { Regra de três. } \\
\text { Sistema de medidas. } \\
\text { Conversão de medidas. } \\
\text { Manuseio e leitura com } \\
\text { instrumentos de medição: escala; } \\
\text { trena; paquímetro; micrômetro; } \\
\text { relógio comparador e apalpador; } \\
\text { goniômetro; régua de seno. } \\
\text { Bloco-padrão. } \\
\text { Calibradores. } \\
\text { Controle Estatístico do Processo } \\
\text { (CEP). }\end{array}$ \\
\hline
\end{tabular}

Fonte: Plano do Curso Técnico em Mecânica (CENTRO PAULA SOUZA, 2001b).

Quadro 8 - Recorte do plano de curso do componente curricular Desenho Técnico Mecânico, evidenciando os elementos relacionados à Matemática

\begin{tabular}{|c|c|c|}
\hline \multicolumn{3}{|c|}{ FUNÇÃO: Planejamento de Projetos } \\
\hline COMPETÊNCIA & HABILIDADES & BASES TECNOLÓGICAS \\
\hline $\begin{array}{l}\text { Correlacionar as } \\
\text { técnicas de desenho } \\
\text { e de representações } \\
\text { gráficas com seus } \\
\text { fundamentos matemáticos } \\
\text { e geométricos, visando sua } \\
\text { interpretação. }\end{array}$ & $\begin{array}{l}\text { Usar as escalas e cortes em desenhos } \\
\text { técnicos, estabelecendo suas relações } \\
\text { com os diversos processos de } \\
\text { fabricação. } \\
\text { Ler e interpretar desenhos técnicos } \\
\text { de conjuntos mecânicos. } \\
\text { Elaborar croquis e desenhos. }\end{array}$ & $\begin{array}{l}\text { Tipos de linhas. } \\
\text { Perspectivas. } \\
\text { Projeções ortogonais. } \\
\text { Escalas. } \\
\text { Cotagem. } \\
\text { Cortes. }\end{array}$ \\
\hline
\end{tabular}

Fonte: Plano do Curso Técnico em Mecânica (CENTRO PAULA SOUZA, 2001b).

Esse cenário nos revela que a Matemática perpassa os currículos dos cursos investigados como base tecnológica definida para profissionalização do técnico. Assim, uma fragilidade no processo de formação matemática desses pro- fissionais poderia comprometer a construção dessas competências e habilidades.

Os professores investigados relatam que têm certa dificuldade de lidar com o ensino de Matemática por conta da defasagem de 
conteúdos com que os alunos chegam nos cursos técnicos; apontando, principalmente, as deficiências relativas aos conteúdos: Equação, Função, Inequação, Regra de Três, Potenciação e Números Complexos. Todos chamaram atenção para o fato de o tema Números Complexos não ser mais tratado pelos professores do Ensino Médio. Os professores relataram ainda que parte dos alunos é desmotivada a aprender Matemática. 0 professor André ressalta que, a seu ver, tal desinteresse tem se acentuado com o tempo.

Eu tenho um banco de provas que eu tenho todas as provas, e se eu pegar uma prova que eu dei há cinco anos atrás, e aplicá-la hoje, provavelmente o cara não sabe resolver, então você tem que enfraquecer um pouco seu nível, porque, se eu forçar aqui, não vai. Isso é estranho. A Matemática está ficando enfraquecida de uns cinco, seis anos para cá. É o que eu sinto. (ANDRÉ, 13 anos de experiência docente na EPT, 2016).

Contudo, eles se sentem incomodados e tentam desafiar a situação fazendo mudanças em suas metodologias de ensino.

[Para lidar com essa dificuldade] a gente vira do avesso, tenta. Você já não dá aula mais, você começa a fazer show. Tem que ir lá, chamar atenção. Você tem que chamar a atenção do aluno. É muito ruim você ter aquele aluno que diz que não gosta, que odeia. Então você começa a fazer uma conta o aluno já reclama. Não sei se o Ensino Médio perdeu um pouco daquela magia, porque, quando eu estudei, eu tive professores que me atraíram para Matemática. Então hoje em dia eu tento fazer isso, atraí-los. E você tem que tirar esse estigma de que é difícil. Tem que mostrar que é fácil, que ele consegue fazer. 0 que falta muito é confiança na Matemática. 0 aluno fala que não consegue fazer e pronto. E vejo isso no geral, turma após turma. E temos alunos aqui que vieram do ensino público, do ensino particular, alunos que já terminaram o ensino médio há muito tempo, alguns que ainda estão cursando... E a estratégia é essa: Começar a fazer espetáculo lá na frente. (ANDRÉ, 13 anos de experiência docente na EPT, 2016).

Portanto, a fala do professor André representa um cenário observado na investigação: a clareza dos professores da escola em asse- verar a importância da Matemática na formação técnica. Não sabemos, no entanto, se as adaptações feitas nas suas práticas de ensino fomentam a construção de conceitos matemáticos de forma adequada. Quando o professor afirma que começa a tentar atrair o interesse dos alunos com aspectos externos à Matemática ("fazer show"), não podemos concluir a eficácia dessa prática. Não podemos deduzir a presença nem a ausência de práticas que se comprometam com a compreensão conceitual da matemática, a partir da sua contextualização em problemáticas voltadas ao seu perfil profissional. Isso nos é colocado como pergunta para futuras investigações, que incluam a observação de aulas.

Outro fator que corrobora tal cenário de valorização da Matemática é a preocupação da escola em estabelecer estratégias de nivelamento para os alunos que possuem dificuldades matemáticas. A professora Carla nos relata que a escola oferece minicursos aos alunos sobre assuntos que os professores identificam como importantes para formação técnica e que não estão previstos na matriz curricular do curso. Dentre eles, a professora relatou que alguns são específicos de Matemática. Os professores André e Ronaldo apontaram que há uma parceria da escola com uma universidade pública da região, onde os graduandos de cursos de licenciatura em Matemática realizam atendimentos aos alunos dos cursos técnicos para sanar suas dúvidas.

Durante as visitas técnicas, os professores nos relataram que alguns dos alunos que frequentam os cursos técnicos investigados concomitantemente ao Ensino Médio procuram estes cursos para melhorar seu desempenho no vestibular nas disciplinas de Física e Matemática.

\section{Considerações Finais}

Poucos estudos têm se debruçado a investigar a Matemática no contexto da educação profissional, por isso concebemos contribuir 
com a prática de professores que ensinam Matemática nessa modalidade de ensino (GONÇALVES, 2012).

Na investigação, verificamos que a Matemática perpassa a estrutura curricular dos cursos técnicos investigados como base tecnológica necessária para formação do profissional técnico a partir de um currículo fundado em habilidades e competências - configurando-se como conteúdos de ensino. Assim, tal Matemática no contexto desses cursos técnicos da área de indústria (subsequente ou concomitante) é prevista como fundamental para a formação dos profissionais técnicos em nível de currículo prescrito.

Chamamos atenção ao fato de as diretrizes da EPT defenderem que a Matemática deve ser tratada nos cursos técnicos de forma interdisciplinar e contextualizada. Acreditamos que uma perspectiva interdisciplinar da Matemática deva ser calcada em uma construção curricular fundada em uma ação comunicativa, situação que se mostra fragilizada no contexto da escola investigada tendo em vista a verticalização do processo de organização e desenvolvimento curricular dos cursos investigados.

Em relação à contextualização, tal perspectiva se efetiva a partir de uma postura em que o professor que ensina Matemática nos cursos técnicos (concomitantes e subsequentes) - e cabe ressaltar que, em geral, estes não são professores de Matemática - se preocupe com uma formação matemática contextualizada a partir de problemas laborais enfrentados pelos técnicos. Pressupomos ainda que tal contextualização deva ir além de uma ação instrumental, e, para tanto, deva tomar como base uma noção de trabalho que supere sua natureza meramente mercadológica.

Finalmente, acreditamos que devamos avançar em trabalhos que tratem do ensino de Matemática na educação profissional visando compreender a prática pedagógica desses docentes, bem como sua formação. Como sugestão para futuras investigações, colocamos, por exemplo, as seguintes perguntas: qual formação pedagógica que o Centro Paula Souza tem oferecido a seus docentes (em cumprimento da legislação em vigor)? Tal formação está pautada em aspectos meramente de implementação curricular ou em aspectos culturais, sociais, psicológicos e filosóficos que permeiam a educação profissional pública? Desse modo, encerramos nosso diálogo (neste artigo) com a noção de que iniciamos/provocamos uma discussão que se apresenta como urgente e necessária.

\section{REFERÊNCIAS}

BARBOSA, J. C. Modelagem matemática: concepções e experiências de futuros professores. 2001. 253 f. Tese (Doutorado em Educação Matemática) - Instituto de Geociências e Ciências Exatas da Universidade Estadual Paulista (UNESP), Rio Claro, SP, 2001.

BRASIL. Presidência da República. Casa Civil. Lei no 9.394, de 20 de dezembro de 1996. Estabelece as diretrizes e bases da educação nacional. Brasília, DF, 1996. Disponível em: <http://www.planalto. gov.br/ccivil_03/LEIS/L9394.htm>. Acesso em: 26 mar. 2019.

Ministério do Trabalho. Portaria Ministerial no 397, de 9 de outubro de 2002. Aprova a Classificação Brasileira de Ocupações - CBO/2002, para uso em todo território nacional e autoriza a sua publicação. Brasília, DF, 2002. Disponível em: <http://www.mtecbo.gov.br/cbosite/pages/ legislacao.jsf>. Acesso em: 26 mar. 2019.

. Presidência da República. Casa Civil. Decreto no 5.840, de 13 de julho de 2006. Institui, no âmbito federal, o Programa Nacional de Integração da Educação Profissional com a Educação Básica na Modalidade de Educação de Jovens e Adultos - PROEJA, e dá outras providências. Brasília, DF, 2006. Disponível em: <http://www.planalto.gov. br/ccivil_03/_Ato2004-2006/2006/Decreto/ D5840.htm>. Acesso em: 26 mar. 2019.

. Ministério da Educação. Resolução CNE/CEB no 6, de 20 de setembro de 2012. Define diretrizes curriculares nacionais para a educação profissional técnica de nível médio. Brasília, DF, 2012a

Catálogo nacional dos cursos técnicos.

Brasília, DF: MEC/SETEC, 2012b. Ministério da Educação. Parecer CNE/CEB 
no 11, de 9 de maio de 2012. Diretrizes Curriculares Nacionais para a Educação Profissional Técnica de Nível Médio. Brasília, DF, 2012c. Disponível em: <https://goo.gl/WiqPUq>. Acesso em: 26 mar. 2019.

CENTRO PAULA SOUZA. Plano de curso: técnico em eletrotécnica. São Paulo, 2001a. Disponível em: <bit.do/eletrotécnica>. Acesso em: 30 maio 2016.

Plano de curso: técnico em mecânica. São Paulo, 2001b. Disponível em: <bit.do/mecanical >. Acesso em: 30 maio 2016.

Estrutura. São Paulo, 2015. Disponível em: $<$ https://www.cps.sp.gov.br/estrutura/\#>. Acesso em: 7 ago. 2015.

FERRER JULIÁ, F. La educación comparada actual. Barcelona: Ariel, 2002.

GADOTTI, M. Perspectivas atuais da educação. Porto Alegre: Artes Médicas, 2000.

GONÇALVES, H. J. L. A educação profissional e o ensino de Matemática: conjunturas para uma abordagem interdisciplinar. 2012. 173 f. Tese (Doutorado em Educação Matemática) - Pontifícia Universidade Católica de São Paulo (PUC-SP), São Paulo, 2012.

GONÇALVES, H. J. L.; DIAS, A. L. B.; PERALTA, D. A. 0 que dizem professores de uma instituição de educação profissional sobre interdisciplinaridade no ensino de matemática. Ciência \& Ensino, Piracicaba, SP, v. 4, n. 1, p. 24-41, 2015. Disponível em: <http://prc.ifsp.edu.br/ojs/index.php/ cienciaeensino/article/view/797>. Acesso em: 30 maio 2016.

Estudo comparativo sobre o ensino de matemática em currículos de educação profissional técnica: Brasil e Estados Unidos. Bolema, Rio Claro, SP, v. 32, n. 60, p. 31-56, abr. 2018. Disponível em: <http://dx.doi.org/10.1590/19804415v32n60a02>. Acesso em: 30 mar. 2019.

HABERMAS, J. Teoría de la acción comunicativa II: crítica de la razón funcionalista. Madrid: Taurus, 2003.

INSTITUTO NACIONAL DE PESQUISAS EDUCACIONAIS ANÍSIO TEIXEIRA - INEP. Censo escolar da educação básica 2013 - resumo técnico. Brasília, DF, 2013. Disponível em: <http:// portal.inep.gov.br/resumos-tecnicos >. Acesso em: 30 maio 2016.

LOZADA, C. 0. Alternativas de modelagem matemática aplicada ao contexto do ensino de física: a relevância do trabalho interdisciplinar entre matemática e física. In: ENCONTRO NACIONAL DE EDUCAÇÃO MATEMÁTICA, 9., 2007, Belo Horizonte. Anais... Belo Horizonte: Sbem, 2007. p. 1-15. Disponível em: <http://goo.gl/xDvqqe>. Acesso em: 30 maio 2016.

MEEDER, H.; SUDDRETH, T. Common core state standards \& career and technical education: bridging the divide between college and career readiness. Washington: Achieve Inc, 2012. Disponível em: <http://goo.gl/HZWOcx>. Acesso em: 30 maio 2016.

PASSOS, R. D. F. O Centro Estadual de Educação Tecnológica Paula Souza (CEETEPS): breve história e perspectivas. Dialogia, São Paulo, v. 5, p. 67-71, 2006. Disponível em: <https://doi.org/10.5585/ dialogia.v5i0.888>. Acesso em: 30 mar. 2019.

PILZ, M. International comparative research into vocational training: methods and approaches. In:

(Ed.). The future of vocational education and training in a changing world, 2012. p. 561588.

SÃO PAULO. Indicação CEE no 8, de 5 de julho de 2000. Diretrizes para Implementação da Educação Profissional de nível Técnico no sistema de ensino do Estado de São Paulo. São Paulo, 2000.

. Deliberação CEE no 97, de 25 de fevereiro de 2010. Fixa normas para credenciamento e recredenciamento de instituições de ensino e autorização de cursos e programas de educação a distância, no ensino fundamental e médio para jovens e adultos e na educação profissional técnica de nível médio, no sistema de ensino do Estado de São Paulo. São Paulo, 2010.

Deliberação CEE no 105, de 10 de fevereiro de 2011. Dispõe sobre as diretrizes para elaboração e aprovação de Plano de Curso e emissão de Parecer Técnico para cursos de Educação Profissional Técnica, presencial ou a distância, e dá providências correlatas. São Paulo, 2011.

Recebido em: 23/04/2017 Aprovado em: 18/01/2019 